\title{
System Thinking, Evaluations and Learning - Experience from Road Construction Megaproject in Algeria
}

\author{
Youcef J-T. Zidane \\ Department of Mechanical and Industrial Engineering, \\ Norwegian University of Science and Technology,Trondheim, Norway \\ Bjørn Otto Elvenes \\ Department of Industrial Economics and Technology Management, \\ Norwegian University of Science and Technology, Trondheim, Norway \\ Knut F. Samset \\ Department of Civil and Environmental Engineering, \\ Norwegian University of Science and Technology, Trondheim, Norway

\section{Bassam A. Hussein} \\ Department of Mechanical and Industrial Engineering, \\ Norwegian University of Science and Technology, Trondheim, Norway
}

Doi: $10.2478 / \mathrm{mjss}-2018-0054$

\begin{abstract}
Ex-post evaluation is starting to be recognized in the Algerian different government institutions (e.g., ministries); and evaluation is becoming part of any program or project for two main reasons, justify the legitimacy of the programs and projects, and collect lessons learned for the next similar programs and projects. On the other hand, academicians believe that programs and projects can be improved by conducting proper evaluations and extracting lessons learned. Program/Project evaluation is comprehensive evaluation, which mainly applies to ex-post evaluation. This paper will look closer at an ex-post evaluation of an Algerian highway megaproject based on PESTOL model, this evaluation is already conducted in the period of 2014 - 2016. Considering ex-post evaluation of projects has many purposes and among them is linked to learning and knowledge sharing and transfer. In this regard, the paper describes very briefly the approach used to the post project evaluation. In addition, link it to learning and to other types of evaluations - i.e., ex-ante, monitoring, midterm, terminal evaluations, and using system-thinking approach, and proposes a framework for learning in projects by evaluations. This paper is based on qualitative case study approach.
\end{abstract}

Keywords: project evaluations, system thinking, PESTOL Model, megaproject, lessons learned

\section{Introduction}

Suchman (1967) mentioned that all social institutions are required to provide evidence of their legitimacy, usefulness and effectiveness in order to justify society's continued funding. Scriven (1991) specified that evaluation is "the process of determining the merit, worth or value of something". Patton (1997) defines program and project evaluation as "the systematic collection of 
information about the activities, characteristics, and outcomes of programs for use by specific people to reduce uncertainties, improve effectiveness, and make decisions with regard to what those programs are doing and affecting". Patton's (1997) definition is concerned more about ex ante monitoring and midterm evaluations. However, our concerns are more about the ex post evaluation. There are five types of evaluations, which are are ex ante (e.g., Samset 2003) monitoring (previous Section 9.3.1), midterm (e.g., JICA, 2004), terminal (e.g., JICA, 2004) and ex post evaluations (e.g., UNIDO, 1972; USAID, 1979; UWA, 1996; NORAD, 1999; OECD, 2002; JICA, 2004; Samset, 2003; Zidane et al., 2016). Evaluation of major governmental projects and programs has existed for more than six decades.

The OECD (2002) has defined evaluation as "A systematic and objective assessment of an ongoing or completed project, program or policy, its design, implementation and results." Ex post evaluation can be described as an evaluation of an intervention after the intervention has been completed (Samset, 2003). In addition, ex post evaluation is conducted after a certain period following the completion of a target project, with emphasis on the effectiveness and sustainability of the project. Such evaluations aim to derive lessons and recommendations for the improvement of future projects and programs (OECD, 2002; Samset, 2003; Zidane et al., 2016). Worsley (2015) mentions that ex post evaluation can serve multiple purposes, of which the two primary ones are learning and/or improvement and accountability and/or control.

Zidane et al. (2016) developed an ex post evaluation model, which they named the PESTOL model (Project Evaluation on Strategic, Tactical and Operational Levels). Their model is based on an existing model (e.g., UNIDO, 1972; USAID, 1979; UWA, 1996; NORAD, 1999; OECD, 2002; Samset, 2003; JICA, 2004). The PESTOL model, presented in next section, considers all project levels, i.e., the strategic, tactical and operational levels. In addition, for measuring success it uses the concepts "efficiency," "effectiveness," "relevance," "impact" and "sustainability."

In this paper, we will link the different types of evaluations with learning, for the ex-post evaluation the PESTOL model is used to that purpose. The other evaluations are mentioned in the context without giving a detailed way of using them.

\section{Theoretical Framework}

When discussing about the lessons learned and evaluation, it is relevant to look at the degree of success and/or failure connected with the project in holistic view, to be able to evaluate the project more constructively. Moreover, how post-project success (and/or failure) are defined based on the evaluation criteria, such as efficiency, effectiveness, relevance, impact, and sustainability, and that is based on the PESTOL model. Furthermore, since the case study is a megaproject, theory about learning in megaproject is presented. Last, but not least, the link between system thinking, evaluation and learning is discussed briefly.

\subsection{Post-project evaluation - PESTOL model}

Zidane et al. (2016) developed an ex-post evaluation model, which they named PESTOL model (Project Evaluation on Strategic, Tactical and Operational Levels). Their model is based on the existing model (e.g., Samset, 2003; JICA, 2004; OECD, 2002; NORAD, 1999; UWA, 1996; USAID, 1979; UNIDO, 1972). The PESTOL model presented in figure 1, considers all the project levels, which are the strategic, tactical, and the operational levels. And using for measuring the success (and/or failure) the concepts "efficiency", "effectiveness", "relevance", "impact", and "sustainability". "Efficiency" reflects a short-term perspective; in this respect, the discussions is particularly associated with cost and time overrun. These aspects can easily be measured. According to Samset (2003), the relevance of the project and its effects, and whether the project attains its goals and objectives measured in terms of effectiveness, impact and sustainability; these measures can only be verified at a well ahead stage, after the project has delivered its results. These are much wide-ranging aspects and are therefore hard to assess (Zidane et al., 2016). 


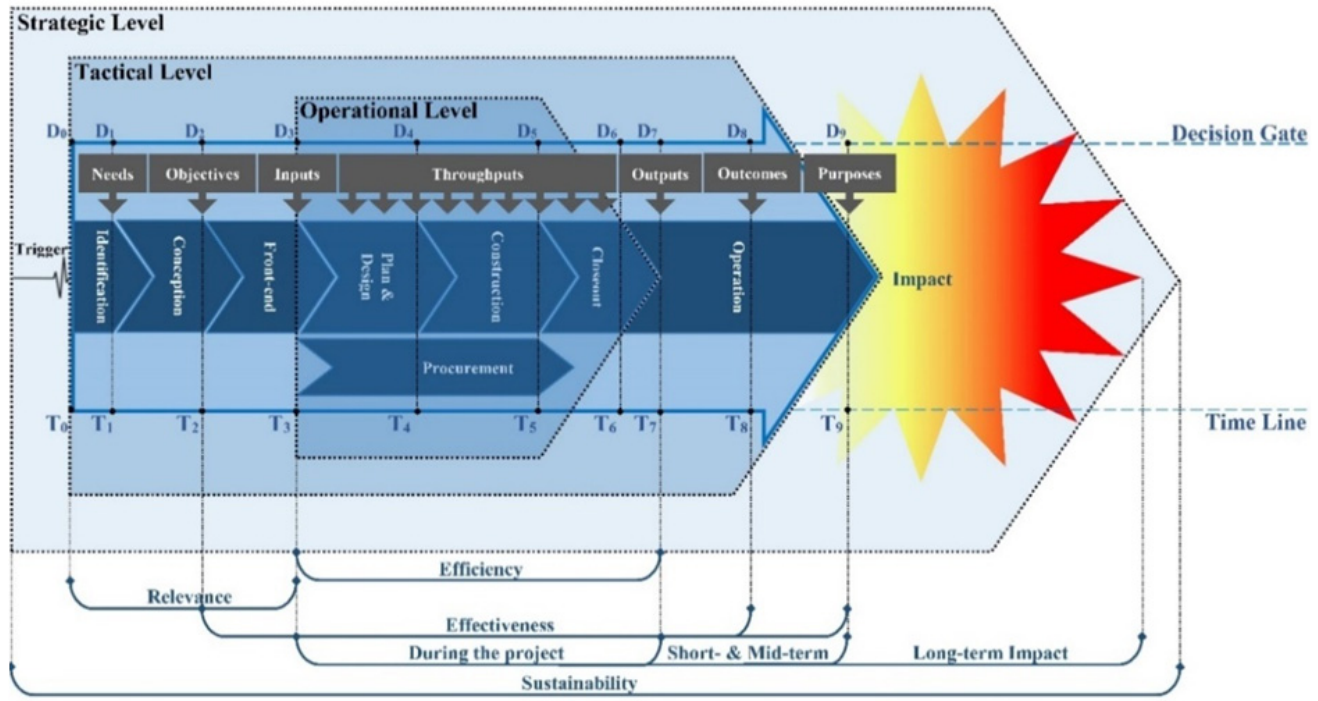

Figure 1. PESTOL model (Zidane el al., 2016)

Zidane and Olsson (2017), Zidane et al. (2016, 2015a, 2015b) define project "Efficiency" as "the question of doing things right and producing project outputs in terms of the agreed scope, cost, time and quality". They added that "quality is not a constraint per se, but often a by-product of the other three factors (scope, time and cost), and one that generally suffers when the others are not properly managed". "Effectiveness" is a measure of the extent to which management attains its objectives (Zidane et al., 2017, 2016; Samset, 2003; OECD, 2002). Samset (2003) and cited in Zidane et al. (2015a, 2015b), "Impact" is defined as "all unexpected positive and/or negative changes and effects of the project, both in the short term and the long term". Zidane et al. (2016) divided "Impact" as evaluation criterion into the following levels: during the project impact, the short-term and mid-term impact, and the long-term impact.

Samset (2003) defines relevance as "an overall assessment of whether a project is in harmony with the needs and priorities of the owners, the intended users and other attested parties. A change in policies or priorities could imply that a project is assigned lower priority, or that it loses some of its rationale. It becomes less relevant". According to Zidane et al. (2016), relevance deals with the needed time window, which starts at time T0, and end at time T3, to make the right decision D3 to start the implementation of the project - i.e., GO for the project. If the decision is to go for the project, and while implementing it, if the project becomes less relevant because of some reasons (e.g., a change of policies or priorities), the evaluation of relevance will instead be handled further by effectiveness, impact, and sustainability. Where "sustainability" is the measure of whether the benefits of an activity are likely to continue after donor funding has been completed and/or withdrawn. On the other hand, the projects require being environmentally and financially sustainable (Zidane et al., 2016; Samset, 2003; OECD, 2002).

\subsection{Lessons learned from megaprojects}

Lessons learned represent important experiences or insights that will have significant consequences for future projects (Schindler and Eppler, 2003). Knowledge sharing both between projects and between them and the parent organization is considered an important factor for achieving organizational success (Cooke-Davies, 2002). A number of researchers such as Robertson et al. (2008), Riege (2005), Nahapiet and Ghoshal (1998) suggest that companies that are concerned with knowledge sharing may have a competitive edge. Due to temporary nature of 
any project, there is a risk of the collected knowledge being lost when the project is completed. Additionally, the practice of having temporary positions, such as advisors and consultants, can lead to loss of knowledge when the holders of those positions complete their tasks and leave the organization. Thus, it is necessary to establish good processes for mapping and documenting different types of knowledge, both during the project and at its completion. It is also necessary for the company to make this body of knowledge available for use in its next project. Lessons learned thus reflect the collective memory of all those who were involved in the project. In such lessons, the emphasis is on two tasks (PMI, 2013):

1. Mapping the drivers for success. Drivers for success include measures or strategies that have been used along the way to achieve desired results.

2. Mapping the challenges that the project had to deal with, the causes and consequences of those challenges, and the measures used to respond to them.

The ability to map and clarify success factors and challenges is a valuable management tool, and can lead to:

- Justification for any changes or adjustments needed.

- An empirical basis for questioning the methods used, such as leadership style, working culture, and other prerequisites for success.

According to Zidane et al. (2013), megaprojects has significantly larger scale and scope than any average industry projects, and they are unique in their nature. The uniqueness also points out that there is a huge potential for creation of new knowledge, not limited to a product or a service, but a new processes through which the products and services are made. Eriksson (2013) presents a description of exploiting and exploring knowledge. (1) Exploration includes things captured by terms such as search, diversity, adaptability, risk taking, experimentation, flexibility, innovation, and long-term orientation. (2) Exploitation on the other hand involves refinement, alignment, control, constraints, efficiency, and short-term orientation.

Eriksson (2013) argues that knowledge exploration can be compared to double-loop learning, in which the predefined boundary will be questioned and subsequently changed. A kind of out-ofbox thinking (by asking the fundamental questions: Why do we do what we do? Why do we do it in the way we do?), experimentation and hopefully an innovative solution would then result in. Megaprojects are possible arenas for creation of new knowledge. Out-of-box thinking can be done through critical reflection, by asking fundamental questions regarding the current practices.

Hammer and Champy (1995) presented first these questions when they talked about the concept of business process reengineering. Asking the fundamental questions and the reflection can lead to identify a gap between current solutions (current practice) and desired solutions (future practice). In order to create the desired solutions that are expected in the megaproject, the existing framework or norms are to be challenged and changed. The double-loop learning can then take place.

Existing knowledge can prevent from learning new things. Dybå (2000) says, "However, organizational improvisation does not emerge from thin air. Instead it involves and partly depends on the exploitation of prior routines and knowledge. ... Hence improvisation mixes previously learned lessons with the current settings contingencies". Knowledge sharing is a central element in knowledge exploitation, and it is primarily connected to single-loop learning (Eriksson, 2013).

Based on the inherent uniqueness of megaproject, it may focus more on knowledge exploration than knowledge exploitation, at least at a higher level. Nevertheless, when it comes to the operational level, there are possibilities for knowledge sharing and knowledge exploitation (Eriksson, 2013; Hussein, 2013; Hussein \& Hafseld, 2013; Hussein et al., 2015).

Megaproject can be considered as a success or failure in terms of many factors; for instance, efficiency, effectiveness, impact and sustainability (e.g., Zidane et al., 2016; Samset, 2003). The learning may be attributed to the produced products (Pemsel and Wiewiora, 2013). On the other hand, the learning may also be attributed to a product that is not much relevant or needed when the project is completed; where it is more about success stories (Zidane and Andersen, 2018). However, in this case, learning plays an important role, because it can include various aspects connected to knowledge development at the individual and collective levels - e.g., collaboration with staff from various disciplines, use of new technology, etc. This learning can then be shared 
with colleagues at the respective base-organizations (Pemsel and Wiewiora, 2013; Pemsel and Müller, 2012).

First, we look at knowledge exploration. Knowledge exploration can be compared to doubleloop learning, in which the predefined boundary (a framework or a set of values that govern a wide range of actions) will be questioned and subsequently changed. A kind of out-of-box thinking, experimentation and hopefully an innovative solution would then result in. Megaprojects are possible arenas for creation of new knowledge. Out-of-box thinking can be done through critical reflection, by asking fundamental questions regarding the current practices. The fundamental questions would be:

- Why do we do what we do?

- Why do we do it in the way we do?

Hammer and Champy (1995) present these questions when they talk about the concept of business process reengineering (BPR). Questioning essential questions can be perceived in connection with what Schön calls the "reflective practitioner". He (Schön, 1998: 61) says, "A practitioner's reflection can serve as a corrective to over-learning. Through reflection, he can surface and criticize the tacit understanding that have grown up around the repetitive experiences of specialized practice, and can make new sense of the situation of uncertainty or uniqueness which he may allow himself to experience".

Asking the fundamental questions and the reflection can lead to identify a gap between current solutions (current practice) and desired solutions. In order to create the desired solutions that are expected in the megaproject, the existing framework or norms are to be challenged and changed (Hammer and Champy, 1995). The double-loop learning can then take place. The learning that first happens at the cognitive level because of reflection will then manifest itself in the behavioural realm as concrete actions and solutions (Schön, 1998).

\subsection{System thinking, post-project evaluation and learning}

Post-project evaluation is a process of reflection on what had happened in the project lifecycle, from the days conception stage started until the delivery of the products and using them for the desired purposes. This reflection allows the evaluators to look at specific episodes within a project stage (phase) - e.g., solving problem, approaching difficult situation that took place the evaluated project. This wider perspective can provide a kind of a systemic understanding, since the involved individuals can now see the cause-effect relationships of their work better; they can now know how the elements of their respective work are connected to elements of others' work in the project as well as a broader picture of consequences their work. This new understanding reflects the relevance of systems thinking. Systems thinking looks at not only individual elements that constitute a system, but also the interconnection between the elements of the system (Senge, 2006).

Reflection is a significant part of learning. Schön (1998: 61) says, "Practitioners do reflect on their knowing-in-practice. Sometimes, in the tranquillity of a post-mortem, they think back on a project they have undertaken, a situation they have lived through, and they explore the understandings they have brought to their handling of the case". Reflection can lead to reshape existing mental models and / or create new mental models. As a part of the reflection attention will be centred on, knowing both what was the actual results of the efforts and the expected results. The gap between the actual and expected results will trigger an inquiry. This inquiry will then lead to single-loop or double-loop learning (Argyris and Schön, 1996). Single-loop learning relates to finding a solution within predefined values and framework in order to eliminate the gap. Double-loop learning relates to finding a solution by changing the predefined values and framework in order to eliminate the gap. The knowledge that emerges in this learning process (both single-loop and double-loop learning) can then be applied in current and / or future projects. The learning process can be compared with the model of Forss et al. (1994) in figure 2. 


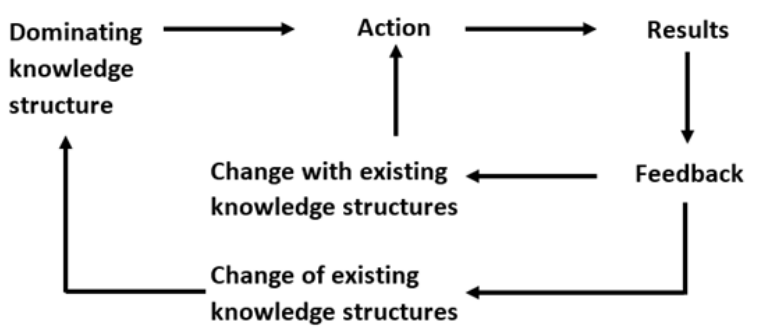

Figure 2. Knowledge structures, feedback, and learning (Forss et al.,1994: 575).

The model of figure 2 is used to reflect the knowledge structures, feedback and learning within projects. However, we will look at the association between knowledge accumulation and sharing, along with learning, and the post project evaluation, then learning and different evaluation types.

Another connection between project evaluation and learning can stem from the reflection on the way the evaluation is made - Can the evaluation and the learning process that is associated with the evaluation process be improved? This connection points out the aspect of meta-learning.

Evaluators who have ambition at containing a user perception frequently select holistic evaluations established on multiple collections of approaches and indicators typically combinations of qualitative and quantitative evaluations (OECD, 2000). Involving systematic thinking approach helps to use the holistic facet of evaluation.

\section{Methodology}

Quantitative method based on case study research strategy is selected to do conduct this research, as described by Yin (2013). Case study strategy is typically a combination of data collection techniques are used such as questionnaires, interviews, archives, and observations. The "evidence" may be quantitative - e.g., numbers, qualitative - e.g., words, or both (Yin, 2013).

A deductive approach, with qualitative research method are used to achieve our research objectives; with primary data (interviews, questionnaires, observations), and secondary data (internal and external documentations and archives).

In the empirical part of this paper, data related to the case was acquired from three main sources: interviews, literature related to the case, and other relevant documents,. More than 30 interviews between contractors, owner, users, and other project stakeholders. Most of the interviews were conducted virtually using electronic mediation (e.g., phone calls). On-site visit was also part of the data collection - Observations - more than 5 visits to sites.

The challenge of this study was more about the reliability and the validity of the gathered data. To reach good validity and high quality of triangulation - besides interviews and the main three sources - other sources had been used to collect the data, such as owner's website and official documents (Ministry of Public Works) and media (archived audio and video records archived newspapers).

Authors associated protocol with this case study; the protocol includes information and evidences - e.g., recording and transcription of the interviews, and codification of the results so that it would adequate the framework for evaluation utilized in this paper case. Reliability in qualitative research can be enhanced by converging on various features. One such feature is transparency. Moisander and Valtonen (2006) describe two aspects of transparency are applied in this research to safeguard reliability: (1) research process transparency and (2) theoretical transparency as ways to improve reliability in qualitative research.

\section{The Case Description}

The cost of East-to-West Algerian Highway megaproject was more than \$US 11.2 Billion, this megaproject is considered most important road project for Algeria and it is the largest public 
megaproject in the world. The date of its completion was planned for the fourth quarter of 2009 , but it was delivered behind schedule by five years. Two main contractors awarded the contract to implement this megaproject. A Chinese contractor for the western part and a Japanese contractor for the eastern part. Including thousands of subcontractors and suppliers from all over the world. The megaproject has created over 100,000 jobs. The project will shorten travel times and provide better and safer access to the north of the country, stimulating economic development (MTP, 2013; Zidane et al., 2015a). It is very important to mention that this case study have been used for other subjects and studies, where some are already published (e.g., Zidane el al., 2016).

The megaproject is a six-lane toll highway. It starts from Morocco's border west to Tunisia's border east, with total length of 1,216 km (line in figure 3). It connects the capital Algiers and all the northern big cities. The development has 12 tunnels, 70 viaducts and 60 interchanges (MTP, 2013; Zidane et al., 2015a). It also includes a provision for building truck stops, service stations and maintenance facilities (MTP, 2013; Zidane et al., 2015a). The case megaproject attributes are summarised in table1.

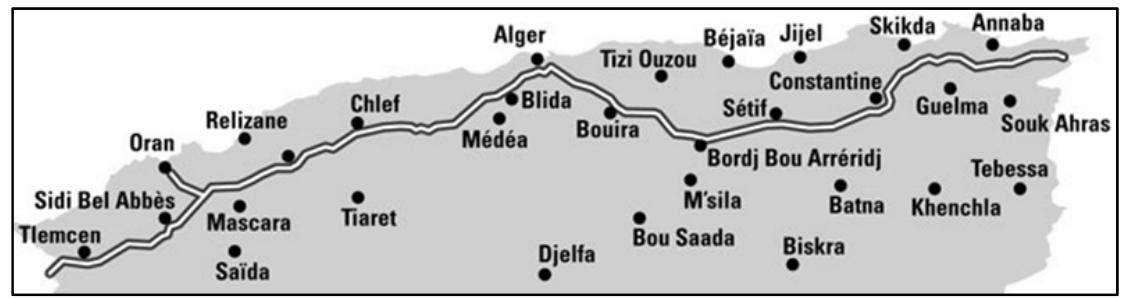

Figure 3. Algeria East-West Highway (MTP, 2013)

The first section is further divided into three sub-sections: the Eastern section, Central section and Western section. The second phase will connect the Maghreb states of Morocco, Algeria, Tunisia and Libya. The construction contract for the $169 \mathrm{~km}$ Central and $359 \mathrm{~km}$ Western sections were awarded to a Chinese contractor. The $399 \mathrm{~km}$-long Eastern section, the largest part of the project, includes 190 bridges and viaducts, and 5 tunnels.

Table 1. The Case Summary (Zidane et al., 2016)

\begin{tabular}{lll}
\hline Attributes & Description & \\
\hline Budget / Cost & Estimated project cost: & < US\$ 7 Billion \\
& Final project cost: & > US\$ 41.2 Billion \\
Schedule & Project cost overrun: & Late 2006 \\
& Starting implementation: & Planned implementation finish date: \\
& Implementation finish date: 2009 \\
& Project delivery behind Schedule: $\quad$ Late 2014 \\
& The total length of the highway is 1,216 km. including: \\
Scope & 12 tunnels & \\
& 70 viaducts & \\
& 60 interchanges & \\
& Truck stops, service stations and maintenance facilities \\
Quality of & The quality of the highway is high in the average, but in some parts, the quality of the \\
deliverables & road was from very bad quality and the necessity in redoing it again. \\
\hline
\end{tabular}

The 1,200 km stretch of the highway will use a base course of cement-treated gravelly sand, rested $20 \mathrm{~cm}$ thick. Succeeding a $14 \mathrm{~cm}$ bituminous bound base, the road will be coated with 6 to $8 \mathrm{~cm}$ of asphaltic concrete. The Eastern section is the largest, with a cost of US\$ 5 Billion, it will include 43 bridges on the main route and 3 tunnels. Around 110 million cubic meters of earth will be moved and about 1.93 million cubic meters of concrete used during the implementation of this megaproject. 


\section{Connecting different evaluation types}

Pemsel and Weiwiora (2013) mentioned, "The risk of knowledge loss at the projects end is a serious problem for Project-Based Organizations". While Zidane et al. (2015a) argue that learning lessons from project reviews is important and an fundamental part of the learning in organization. There are solutions for this issue. One of the solutions is to look at what has occurred in the project and assess it - at the end, which is named by terminal evaluation. And / or at different points of time during the project; which is called monitoring according to PMBOK Guide (PMI, 2013).

We now look at evaluations and learning, based on systematic thinking. This may address issues such as; how did the project achieve knowledge during the project based on mid-term and terminal evaluations, and from previous experiences based on ex-post evaluations? How well did they spread this learning within the project team based on monitoring and control, and how relevant stakeholders are well involved in the early project phases during the conception and front-end planning, based on ex-ante evaluation? Finally, how all these types of evaluations are linked to each other?

There is a relationship between the 5 evaluations types, the timing and the relationships of using each type of evaluation are shown in figure 4 and figure 5. The five evaluations are "ex-ante", "monitoring", "mid-term", "terminal", and "ex-post" evaluations; these evaluations are defined.

Ex-post evaluation - e.g., PESTOL model in this paper, this evaluation is conducted after a certain period has passed since the completion of a project, and it is conducted with an emphasis on the efficiency, effectiveness, relevance, impact and sustainability of the project (Samset 2003; Zidane et al., 2016). This evaluation is aimed at deriving lessons and recommendations for improvement and for the planning and implementation of more effective and efficient projects (JICA, 2004; Samset 2003; Zidane et al., 2016).

Terminal evaluation is performed at the completion of the project, focusing on its efficiency, effectiveness and sustainability. Based upon the results of the evaluation, the evaluator determines whether it is appropriate to complete the project or necessary to extend follow-up cooperation (JICA, 2004).

Midterm evaluation is directed at the midpoint of project implementation. This evaluation is aimed at examining the achievements and process of the project, focusing on the efficiency and relevance among the Five Evaluation Criteria. Based upon its results, the original project plan may be revised or the operation structure strengthened if necessary (JICA, 2004).

Ex-ante evaluation involves a study of the project to determine its necessity as well as its conformity. Details of the project and its expected outputs are clarified. Then, the relevance of the project is comprehensively examined and evaluated. In ex-ante evaluation, evaluation indicators are set and used to measure the effect of the project in subsequent evaluation, from the midterm evaluation to the ex-post evaluation (JICA, 2004). According to Cristiano and Proietti (2014), "exante evaluation concerns the process of developing a policy program and is performed before its implementation. The evaluation involves a range of stakeholders and acts as a critical mirror for the authorities responsible for program development. It provides an assessment of whether development issues have been diagnosed correctly and should identify any gaps; whether the strategy and objectives proposed are relevant to national and regional needs; whether the approach proposed is coherent, and consistent with Community policies and guidelines; whether the assumptions concerning expected results and impacts are realistic and in line with the resources available. This process should enable successive drafts of the program to be refined and improved so that it is more likely to achieve its objectives in a cost-effective manner. Moreover, exante evaluation sets the cornerstone for subsequent monitoring and evaluation activities, by ensuring that all necessary information is available and that the system is adequate to provide the data needed to assess the program's results and impacts. This prepares the ground for reliable monitoring and evaluation throughout the programming period, which contributes to successful program steering and demonstration of the program's achievements."

Monitoring is referred to in the PMBOK Guide as follows: "to monitor is to collect project performance data with respect to a plan, produce performance measures, and report performance information." And "monitoring and controlling processes are those processes required to track, 
review, and regulate the progress and performance of the project; identify any areas in which changes to the plan are required; and initiate the corresponding changes" (PMI, 2013). This process can accumulate lesson learning and knowledge on the project operation level to be used in other similar projects. Monitoring is happening throughout the project.

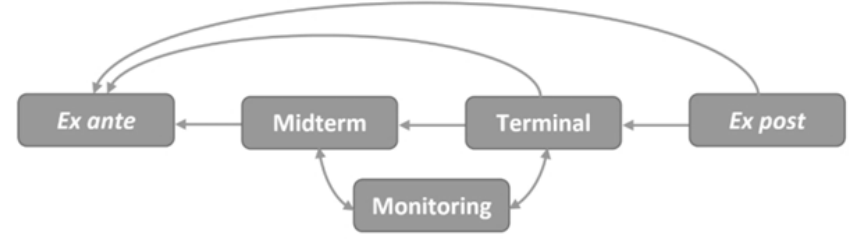

Figure 4. The relationships between evaluations and learning.

The project group gains and accumulate experiences through doing and working on the tasks. It could be of advantage to use the same project group in similar coming projects, in order to take advantage from the gained experience (Sørensen et al., 2015).

Since a project can be seen as a system, the angle of system thinking is considered here along with how to link it to evaluation and learning. Haskins et al. (2010) define system as a "combination of interacting elements organized to achieve one more stated purpose". Similarly, Blanchard (2004) defines system as "a set of interrelated components working together with the common objective of fulfilling some designated need". Thinking about a system is one definition of systems thinking (Moser, 2013). According to Haskins et al. (2010), there are five foundational elements describing a systems thinking framework: componential, relational, contextual, dynamic and modal elements. The componential, relational, contextual and dynamic elements relate to the system.

Megaprojects as complex systems have a significantly larger scale and scope than average industry projects; the cost associated with them is higher, the time taken for their completion is much longer and there are a large number of organizations involved. In addition, the effect and impact of the megaprojects on society are high. They are unique in terms of, for instance, the underlying principles and assumptions, the concept, the product, the sheer scale and scope of the process through which the product is made, the degree of complexity, and the effect and impact on the larger society. There is a huge potential for the creation of new knowledge regarding a new process through which the products and services are made.

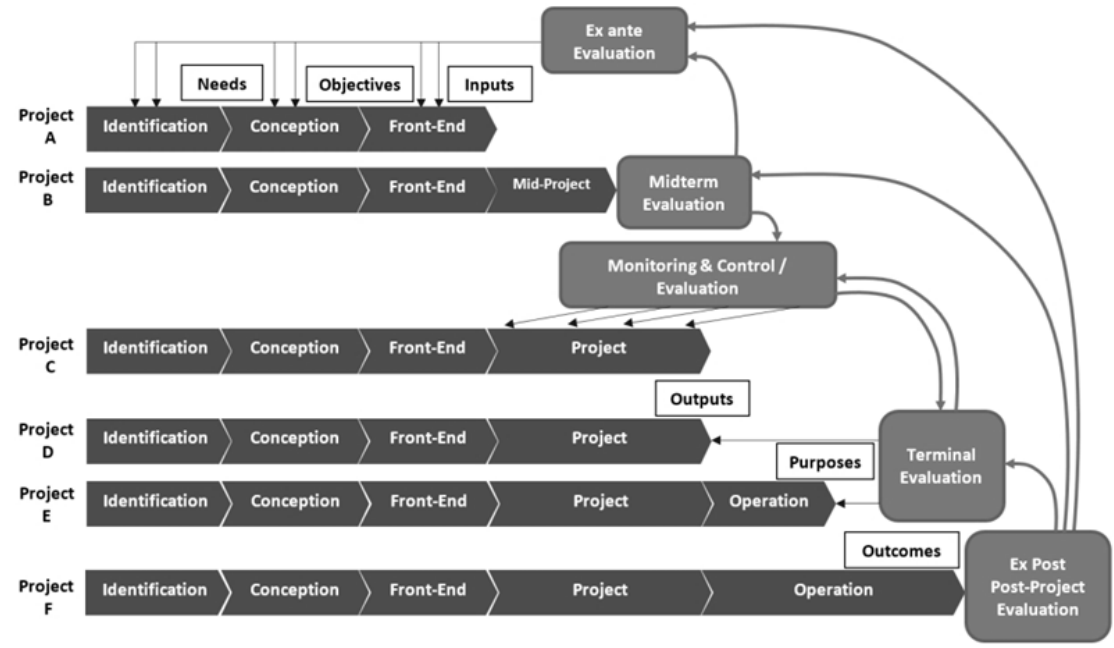

Figure. Timing of each evaluation type use during the PLC. 
The five types of evaluations discussed previously, and the way they are interconnected to each other, based on a systematic thinking, can be among the best ways to harness the current practices with a view to establishing better future practices in upcoming similar projects.

Each type of evaluation can feed other evaluations: In particular, ex-post can feed ex-ante evaluation, since the lessons learned are more concerned with the strategic and tactical level, and these two evaluations happen at the level of the owner/client/sponsor since this stakeholder is more interested in project effectiveness, relevance, impacts and sustainability. Monitoring, midterm and terminal evaluations are more related to the operation level and the efficiency of the project in general; these evaluations are conducted by the contractor, especially "monitoring evaluation," to control the plans better.

\section{Post-project evaluation and lessons learned in the megaproject case}

A study by O'Dell and Hubert (2011) shows that organizations effective at transferring best practices rather than reinventing or ignoring them are more competitive than others. In another study conducted by Carrillo et al. (2013) on accumulating and sharing lessons learned in construction companies, they suggest that sharing lessons learned would main to learning for analogous projects in the future, to avoid redoing mistakes and repeat success, to provide a competitive advantage over other companies, to learn lessons for successive stages of on-going projects.

A megaproject can be considered as a success or failure in terms of many factors; for instance, efficiency, effectiveness and impact. Whatever be the nature of the result, the project contributes to learning. It is also to be noted that existing knowledge can also prevent us from learning new knowledge - e.g., some interviews answered to the question about if they learned from contracted by answering:

"We are used to do it in this way since the day I am in charge of these tasks, in this organisation".

We always want to stick to the existing configurations of thinking, doing things and solutions even if this prevents us from finding better ways to solve the problems and better solutions.

A megaproject, according to its inherent uniqueness, may focus more on knowledge exploration than knowledge exploitation, at least at a higher level. However, when it comes to the operational level, there are possibilities for knowledge sharing and knowledge exploitation.

An evaluation of a project can be seen as process of reflection on what has happened in the project during a specific timeframe. This reflection allows the project team to look at specific episodes of the projects - for example, solving a particular problem, approaching a complex situation that took place earlier in the project - from a wider perspective. This wider perspective can provide a kind of a systemic understanding, since the involved individuals can now see the causeeffect relationships of their work better; they can now know how the elements of their respective work are connected to elements of others' work in the project as well as a broader picture of consequences their work. This new understanding reflects the relevance of systems thinking. Systems thinking looks at not only individual elements that constitute a system, but also the interconnection between the elements of the system (Senge, 2006).

PESTOL model have been used on the case study case - details for the evaluation in the paper Zidane et al. (2016). The evaluation permitted to extract a lessons learned, these lessons learned could be used for the next similar coming projects, especially for the strategic and tactical level. The lessons learned were generated based on the extent the project succeed or failed to meet the planned objectives by comparing them to the realised objectives. Table 2 summarises the planned and realised objectives, and the lessons learned. 
Table 2. Planned vs. realized objectives, and lessons learned (Zidane et al., 2016, 2015b)

\begin{tabular}{|c|c|c|c|}
\hline Measures & Planned objectives & Realised objectives & Lessons learned \\
\hline Efficiency & $\begin{array}{l}1 \text { - Estimated project cost: < } \\
\text { USD } 7 \text { billion } \\
2 \text { - Starting implementation: } \\
\text { late } 2006 \\
\text { - Planned implementation } \\
\text { finish date: late } 2009 \\
3 \text { - Deliver the whole scope }\end{array}$ & $\begin{array}{l}1 \text { - Final project cost: > USD } 11.2 \\
\text { billion } \\
\text { - Project cost overrun: > USD } 4.2 \\
\text { billion } \\
2 \text { - Implementation finish date: late } \\
2014 \\
\text { - Project delivery behind schedule: > } \\
5 \text { years. } \\
3 \text { - Operational but still not completely } \\
\text { delivered }\end{array}$ & $\begin{array}{l}\text { - Improve front-end planning } \\
\text { - Better estimation and giving enough time } \\
\text { to estimators } \\
\text { - Involved all the stakeholders at the front- } \\
\text { end analysis } \\
\text { - Try to be realistic in the plans (time and } \\
\text { cost). } \\
\text { - Giving management and business course } \\
\text { to parliament to let them know the real } \\
\text { costs and needed time for these kinds of } \\
\text { projects } \\
\text { - Creating permanent enterprise in charge } \\
\text { for implementing all road projects. This will } \\
\text { allow the organisation to accumulate } \\
\text { knowledge in implementing road projects. } \\
\text { - Creating local contractors with high } \\
\text { capitals able to contract road megaprojects }\end{array}$ \\
\hline Effectiveness & $\begin{array}{l}1 \text { - Reduce traffic and } \\
\text { shorten travel time }\end{array}$ & $\begin{array}{l}1 \text { - Objective met } \\
2 \text { - Reduce carbon dioxide emission } \\
3 \text { - Fewer accidents compared to on } \\
\text { previously used road }\end{array}$ & $\begin{array}{l}\text { - Improve front-end planning } \\
\text { - Making decision based on realistic plans. } \\
\text { - Do not interfere in the projects } \\
\text { implementation } \\
\text { - Hiring more advisers and experts in these } \\
\text { type of projects. } \\
\text { - Improving the Measure Of Effectiveness } \\
\text { (MOE) system within the ministry }\end{array}$ \\
\hline Relevance & $\begin{array}{l}1-\text { Time-saving and } \\
\text { increase the fluidity in traffic }\end{array}$ & 1 - Objective met & $\begin{array}{l}\text { - Improve conception phase decision } \\
\text { process } \\
\text { - Improve the front-end planning }\end{array}$ \\
\hline Impact & $\begin{array}{l}1 \text { - Create temporary } \\
\text { employment }\end{array}$ & $\begin{array}{l}1 \text { - Creation of more than } 100,000 \text { jobs } \\
2 \text { - Destruction of houses and trees } \\
\text { standing in the way of the project }\end{array}$ & $\begin{array}{l}\text { - Continuous improvement by evaluation } \\
\text { - Full delegations of the projects to the } \\
\text { created enterprise in charge for } \\
\text { implementing these projects. } \\
\text { - Being more proactive to forecast and } \\
\text { realisation only of positive impacts. }\end{array}$ \\
\hline Sustainability & $\begin{array}{l}1 \text { - Cover the maintenance } \\
\text { of the highway from its } \\
\text { income in the operational } \\
\text { phase } \\
2 \text { - Enlarging the } \\
\text { transportation network by } \\
\text { other highways }\end{array}$ & $\begin{array}{l}1 \text { - The highway will not generate any } \\
\text { income since its usage will be free until } \\
2017 \\
2 \text { - The highway has highlighted the } \\
\text { gaps in the existing transportation } \\
\text { network, which has made the } \\
\text { government consider further } \\
\text { expansions }\end{array}$ & $\begin{array}{l}\text { - Improve conception phase decision } \\
\text { process } \\
\text { - Improve the front-end planning } \\
\text { - Involve academia and researchers related } \\
\text { to the industry }\end{array}$ \\
\hline
\end{tabular}

The project is evaluated to have a high relevance and effectiveness in tactical level compared to the strategic objectives and operational level. The project appears to have had optimistic impacts on the regularity and number of passengers on the highway. The implementation process is evaluated to be complete failure. Huge overruns in time, cost and SHE is what gives a lowest score on efficiency than the other evaluation criteria. Table 2 shows the planned and realized objectives based on each criterion.

In the early phase of the project, information about similar projects are gathered to obtain knowledge on how these projects where done and what can be learned from them (Zidane et al., $2015 b)$. The information is gathered through documents concerning previous projects, on-site inspections and contact with the project managers on the previous projects, but this project case was unique and no many similarities with the previous once. The documentations of projects are saved in papers databases. The searchable database makes it very hard to access the documentation. This can be explained by the closing the loop of evaluation between the ex-post and ex-ante evaluations.

The interviewees mentioned that similar extension projects had seen better strategic decisionmaking from the organisation in charge for implementing these type of projects created by the owner (Ministry of Civil Work, MTP). Improvement of the decision-making quality process had 
saved several months, even years for running road construction megaprojects compared to the case presented in this paper. This improvement came from the errors committed in the decisions made in the case and using the lessons learned for upcoming projects.

The Algerian Public Works represented by "National Enterprise for roads construction" cooperates for instance with the Algerian Railway administration belonging to the ministry of Transportation, also with the ministries of Agriculture and Rural Development, of environment management, of Housing, Urban Development and the City. The cooperation will touch all the future new Highway megaprojects construction. This cooperation came after the understanding of the sponsor the value of involving the major stakeholders in the early phases of any coming future projects.

\section{Conclusions}

The aim of this paper is to investigate the relation between evaluation, knowledge and learning in a holistic approach. We have considered diverse approaches to learning, and different approaches to evaluation, and proposed a model to link the different evaluation types.

The PESTOL model was used to evaluate our case, where various aspects are clarified to show how to overcome some of the potential challenges in program/project improvement from the lessons learned based on the ex-post evaluation and system thinking.

Ex-post evaluation already conducted, used to illustrate the link to ex-ante and monitoring for coming similar projects.

The model presented in this paper, which links all the five types of evaluations can be used as an integrated model for organizations to evaluate continuously their projects and accumulate lessons for coming similar projects and apply them depending on which timing and phase is the current projects.

\section{References}

Argyris, C., \& Schön, D.A. (1996). Organisational learning II: theory, method, and practice. Reading. MA.: Addison-Wesley.

Blanchard, B.S. (2004). System engineering management. Hoboken: John Wiley.

Boud, D.; Keogh, R.; \& Walker D. (1996). Reflection: Turning Experience into Learning. London: Kogan Page.

Carrillo, P., Ruikar, K., \& Fuller, P. (2013). When will we learn? Improving lessons learned practice in construction. International Journal of Project Management, 31, 567-578.

Cooke-Davies, T. (2002). The 'real' success factors on projects. International Journal of Project Management, 20, 185-190.

Cristiano, S., \& Proietti, P. (2014). Farm Innovation through Rural Development Programmes 2014-2020: an evaluation model of the EIP. In 11th European IFSA Symposium, Farming Systems Facing Global Challenges: Capacities and Strategies, Proceedings, Berlin, Germany, 1-4 April 2014 (pp. 141-152). International Farming Systems Association (IFSA) Europe.

Dybå, T. (2000). An instrument for measuring the key factors of success in software process improvement. Empirical software engineering, 5, 357-390.

Eriksson, P.E. (2013). Exploration and exploitation in project-based organizations: Development and diffusion of knowledge at different organizational levels in construction companies. International Journal of Project Management, 31, 333-341.

Forss, N., Salmelin, R., \& Hari, R. (1994). Comparison of somatosensory evoked fields to airpuff and electric stimuli. Electroencephalography and Clinical Neurophysiology/Evoked Potentials Section, 92, 510-517.

Hammer, M., \& Champy, J. (1995). Reengineering the corporation - A manifesto for business revolution. New York: Harper Business.

Haskins, C., Forsberg, K., Krueger, M., Walden, D., \& Hamelin, R.D. (2010). INCOSE Systems Engineering Handbook v. 3.2: A guide for system life cycle processes and activities. CA: INCOSE.

Hussein, B. (2013). Factors Influencing Project Success Criteria. Proceedings of the 2013 IEEE 7th International Conference on Intelligent Data Acquisition and Advanced Computing Systems, 02, 566-571.

Hussein, B., \& Hafseld, K. (2013). Impact of organizational factors on information system project. Proceedings of the 2013 IEEE 7th International Conference on Intelligent Data Acquisition and Advanced Computing Systems, 02, 591-596. 
Hussein, B., Ahmad, S.B.S., \& Zidane, Y.J-T. (2015). Problems Associated with Defining Project Success. Procedia Computer Science, 64, 940-947.

JICA - Japan International Cooperation Agency. (2004). JICA Guideline for Project Evaluation - Practical Methods for Project Evaluation, Tokyo: JICA.

Moisander, J., \& Valtonen, A. (2006). Qualitative marketing research: a cultural approach. London: Sage Publications.

Moser, H.A. (2013). Systems Engineering, Systems Thinking, and Learning: A Case Study in Space Industry. Switzerland: Springer.

MTP - Ministère des Travaux Publics et des Transports. (2013). The East-West Highway. [Online] Available: http://www.mtp.gov.dz/ (October 31, 2014).

Müller, R., Pemsel, S., \& Shao, J. (2014). Organizational enablers for governance and governmentality of projects: A literature review. International Journal of Project Management, 32, 1309-1320.

Nahapiet, J., \& Ghoshal, S. (1998). Social capital, intellectual capital, and the organizational advantage. Academy of Management Review, 23, 242-266.

NORAD. (1999). The Logical Framework Approach, Handbook for objectives-oriented planning. Norway: NORAD.

O'Dell, C., \& Hubert, C. (2011). The new edge in knowledge - How knowledge management is changing the way we do business. New Jersey: John Wiley \& Sons, Inc.

OECD. (2002). Glossary of key terms in evaluation and results based management. Paris: OECD.

Patton, M.Q. (1997). Utilization-Focused Evaluation: The New Century Text. CA: Sage Publications.

Pemsel, S., \& Wiewiora, A. (2013). Project management office a knowledge broker in project-based organisations, International Journal of Project Management, 31, 31-42

Pemsel, S., Müller, R. (2012). The governance of knowledge in project-based organizations, International Journal of Project Management, 30, 865-876.

Pemsel, S., Wiewiora, A., Müller, R., Aubry, M., \& Brown, K. (2014). A conceptualization of knowledge governance in project-based organizations. International Journal of Project Management, 32, 1411-1422.

PMI - Project Management Institute (2013). A Guide to Project Management Body of Knowledge. (5th Ed.). PA: Newtown Square.

Riege, A. (2005). Three-dozen knowledge-sharing barriers managers must consider. Journal of Knowledge Management, 9, 18-35.

Robertson, B., Beruvides, M.G., \& Daniel, B. (2008). A software-based lessons learned management system: Enhancing knowledge management in organizations. IIE Annual Conference Proceedings, 787-792.

Samset, K. (2003). Project Evaluation: Making Investments Succeed. Trondheim: Tapir Academic Press.

Schindler, M., \& Eppler, M.J. (2003). Harvesting project knowledge: A review of project learning methods and success factors. International Journal of Project Management, 21, 219-228.

Schön, D. (1998). The reflective practitioner - How professionals think in action. New York: Basic Books.

Scriven, M. (1991). Evaluation thesaurus. Newbury Park, California: Sage Publications.

Senge, P.M., (2006). The Fifth Discipline - The art and practice of the learning organization. New York: Random House Business Books.

Sørensen, K., Pelikan, J. M., Röthlin, F., Ganahl, K., Slonska, Z., Doyle, G., ... \& Falcon, M. (2015). Health literacy in Europe: comparative results of the European health literacy survey (HLS-EU). European journal of public health, 25, 1053-1058.

Suchman, E.A. (1967). Evaluative Research: Principles and Practice in Public Service and Social Action Programs. New York: Russell Sage Foundation.

UNIDO - United Nations Industrial Development Organization (1972). Guidelines for project evaluation, New York: UNIDO.

USAID. (1979 ). Practical Concepts Incorporated, The Logical Framework, A Manager's Guide to a Scientific Approach to Design and Evaluation. Washington DC: Practical Concepts Incorporated.

UWA - United Way of America. (1996). Measuring Program Outcomes: A Practical Approach. [Online] Available: http://digitalcommons.unomaha.edu/slceeval/47/ (December 15, 2015)

Weisbrod, B.A. (1960). Does better health pay?. Public health reports, $75,557$.

Weiss, C. (1972). Evaluating action programs: Readings in social action and education. Boston: Allyn and Bacon.

Worsley, T. (2015). Ex-post assessment of transport investments and policy interventions: Prerequisites for expost assessments and methodological challenges. Summary and conclusions of the roundtable. International Transport Forum Discussion Paper.

Yin, R.K. (2013). Case Study Research Design and Methods. (5th ed.). London: SAGE Inc.

Zidane, Y. J-T., \& Andersen, B. (2018). Causes of Delay and their Cures in Major Norwegian Projects. The Journal of Modern Project Management, 5, 80-91.

Zidane, Y. J-T., Johansen, A., Ekambaram, A., \& Hald, L. C. (2015a). When Stakeholders Shape Successes or Bring Failures-A Case Study of an Algerian Megaproject. Procedia Computer Science, 64, 844-851. 
Zidane, Y.J-T., \& Olsson, N. (2017). Project Efficiency, Effectiveness and Efficacy. International Journal of Managing Projects in Business, 10, 621-641.

Zidane, Y.J-T., Johansen, A., \& Ekambaram, A. (2013). Megaprojects-Challenges and Lessons Learned. Procedia - Social and Behavioral Sciences, 74, 349-357.

Zidane, Y.J-T., Johansen, A., \& Ekambaram, A. (2015b). Project Evaluation Holistic Framework - Application on Megaproject Case. Procedia - Computer Science, 64, 409-416.

Zidane, Y.J-T., Johansen, A., Hussein, B.A., \& Andersen, B. (2016). PESTOL - Framework for «Project Evaluation on Strategic, Tactical and Operational Levels». International Journal of Information System and Project Management, 4, 25-41. 